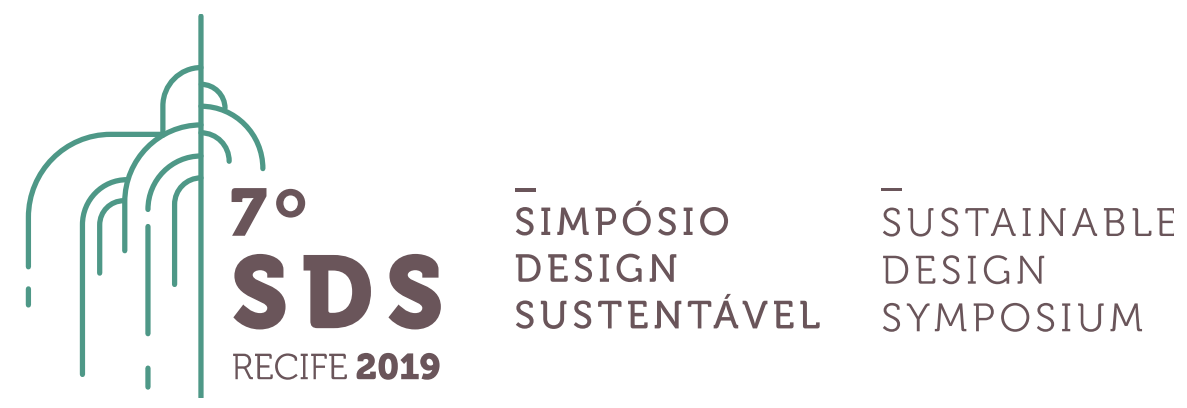

\title{
Social innovation possibilities on food production-consumption relationship: an eye on the design of short food supply chains and the local markets
}

\author{
Ellen Gonzalez, Arquiteta e Urbanista UFPR
}

PUC-Rio, Departamento de Artes e Design, gnzellen@gmail.com

\begin{abstract}
This article will briefly define the two mainstream formats of production / consumption relationship on the food industry and start the discussion of how consumers can be turned into active participants on the process of choosing the provenance of their food, based on the differences of agriculture methods, food production chains and the social, economic and cultural impact of this process. Another aspect of this study is to point out the social, economic and cultural effects of the current production pattern on modern society, and show how the Short Food Supply Chains (SFSC) and Local Agriculture (LA) are possible, feasible and socially innovative alternatives, by highlighting their advantages under all perspectives of sustainability. As an example of this practice, the case of Junta Local in Rio de Janeiro, Brazil will be presented.
\end{abstract}

Keywords. food, sustainable, local, fair trade, service design, short food supply chain.

\section{Food for thought}

The aim of this article is to discuss the multiple alternatives for the standard agriculture production methods and food distribution, as well as the importance of shortening the economic, social and cultural distances between both ends of the food chain: producers and final users. The matters and impact of the current food production mechanisms versus a short chain market will be presented, based on local agriculture, small and artisanal production complemented by direct contact with the final consumer and its cultural, economic and social impacts; and how much design for social innovation concepts, tools and projects can help in strengthening and implementing these ideas and practices.

The observation of the market growth tendencies, Globalization, and standardization of food consumption and the multiple impacts of these processes have been raising questions and inquietude for a long time. On the past decade, these issues have become more and more worrisome, and people started considering how little they know about the origins of what they 
eat: Where is it cultivated? How far from their table? Who are the people behind it? How do they live? How do they handle the food produced?

In short, the goal is to see food production from fresh lenses, rethinking the food consumption chain, the role of both laborers and end users. How the whole process can be reorganized, valuing the local, hand- made, small-scale. This scenario will be studied through the case of Junta Local, a bottom-up initiative that has put together a group of small producers from Rio de Janeiro, Brazil.

Defining and comparing the two mainstream food production methods is one way of beginning this study: mass food production versus short food supply chain and local agriculture. Following up, it is also necessary to point out the social, economic and cultural effects of the current production pattern on modern society. Short Food Supply Chains (SFSC) and Local Agriculture (LA) are showcased as possible, feasible alternatives. The studies will be based on bibliographical research and the observations from an insider perspective of Junta Local, from July 2016 to December 2017.

\section{Food chains}

A basic definition of the current and worldwide largely practiced Agribusiness, as defined by Goldberg and Davis (1975) "... is the sum total of all operations involved in the processing and distribution of products produced on a farm, i.e. production operations on a farm, storage, processing, transport and sale of agricultural commodities and items made from them...". A practical approach and application to this definition attribute to the agribusiness concept the task of supplying and feeding the large-scale food industry with agricultural products and services. A more modern view of this business can be described by Steven Sonka who defines agribusiness as

\footnotetext{
"a chain of sub-sectors interconnected by a series of direct and reverse linkages that includes: research, genetic and seeding firms and suppliers of other biological material, suppliers of other inputs, agricultural producers, buyers of agricultural products, processors of the first and second phases of processing the agricultural products to finished products, retail and trade and institutions of public catering." (SONKA, 1999).
}

In a few words, this is a business model in which agriculture is transformed into merchandise, food is turned into a commodity in a system that encompasses various sectors focused on maximizing the food production chain results, generally speaking at a large scale, industrialized production, based on corporate farming as opposed to small-scale family farms.

This business model sustains the ideals of the Green Revolution, a historical landmark on cropping from the late 1950s and 1960s, in which agricultural practices focused on maximum revenue have exposed the land, biodiversity, and planters to all sorts of hazards. To increase food production and minimize or eradicate food import, a number of fertilizers, herbicides, pesticides, and genetic modifications were applied on plants to increase food production and minimize or eradicate food import, so they would yield more per acre. Those practices also decreased the general cost of the crop, since the harvest, from the same piece of land, was bigger.

The Green Revolution has played an important role on feeding ever-growing populations in developing countries like Mexico and India, where starvation rates were alarming in post-war "Baby Boom Era", but the by-products of this methods are uncountable vegetable species extinguished, genetically modified, and plants that can only grow with the aid of synthetics. Not to mention the still unmeasured damage to the soil and human beings in contact with such chemicals. 
Opposing this maximum profit oriented methodology, Local Agriculture, practiced on small, family farms, has sprung, rescuing old times tradition and techniques, as an "alternative" to mass production food chains, and has played an important role over the past decade or so. It encompasses the production, distribution, retail and purchase of food, with focus on involving, as actors, producers and consumers alike.

The concept of Short Food Supply Chains (SFSCs) has emerged around 2000, as a result of a broader debate on "Alternative food chains" (Ilbery and Maye, 2005), "Alternative food networks" (Goodman and Goodman, 2009) or "Sustainable food chains" (Wiskerke, 2009).

According to an action plan developed in 2009 at the Ministry of Agriculture, Agrifood, and Forestry of France SFSC can be defined as "commercialization of agricultural products through direct selling or indirect selling when only one intermediary is involved". The SFSCs have also risen as a form of resilience of the family farms with the support of concerned consumers, local communities, and civil society organizations. Short food supply chains are increasingly taken into consideration by rural and food policies as a driver of change towards sustainability both in the agro-food system and rural areas. SFSCs involve more sustainable ways of producing, processing, and/or selling food, which demonstrate a turn to quality' in both agriculture and consumption.

The most common examples of this practice are farmers markets, on-farm sales, direct Internet sales, consumer cooperatives, community supported agriculture (CSA) and urban gardens. It is important to emphasize that Short, in the Short Food Supply Chains, refers to geographical, economic and social distances, by minimizing the length traveled, creating direct relations between producer and consumer (with none or as few intermediaries as possible), and also by promoting market exchanges within a community or locality.

The currently most practiced food mass-production system, agribusiness, as every other mass production system, is focused on the market, which dictates maximum profitability and minimum time-frame. Food is seen as a commodity, as a marketable object, where region (terroir), soil and health issues do not matter as much as profitability, fulfilling market created demands and consumption standards.

Regional eating patterns are overrun by market assumptions that we can all be fed the same. Globalization has erased seasonality and individual characters of produce and has made all crops look alike, regardless of where and when they are grown. Seeds and vegetable species have been licensed, others completely extinguished, to fit what the mainstream market wants to offer us, around the globe. High productivity is more important than the quality (sensorial, nutritional) of what we eat. With that in mind, agribusiness has focused on lab maneuvering the species, genetically modifying plants to fit business interests.

The results are still unforeseen, as this has happened so intensely in the past decades; humans haven't had the time to feel the effect in the long run. We can definitely see small sparks of these changes, by the ever crescent number of food allergies and intolerances.

When situations rise to be so extreme, an opposite movement is born. An alternative to this situation has already sparkled all over the world. Over the past years, local and organic crops have multiplied, and several initiatives, involving both ends of the chain, are sprouting. Consumers and producers are becoming more interested in each other, developing closer relationships, and getting to know each other better.

SFSCs have empowered producers and consumers, established relations focusing on territorial and sustainability questions, and resulting in bonds based on trust and equality. These newly discovered market demands are a result of the richer communication that is taking place. This agricultural system offers the opportunity for people to eat what the land "gives" and not 
grow what the market demands. The food is produced by people and for people, in all spectrum. Different food for different people, against the standardization of food/consumption.

The impact of the SFSCs permeates and increases the quality of economic, cultural and social aspects. Local farming means working the territory, the locality, minimizing the distances traveled, transportation requirements and expenditures (fuel, emissions). By respecting the small, seasonal, native crops, produce tends to be of better quality in terms of nutrition (pairing consumer needs) and taste. It also provides the chance of organic farming, demands lower utilization of herbicides and pesticides, for the natural ecosystem offers a more balanced environment. The outcome is fresher, healthier products, in a sustainable chain, respecting the values of biodiversity, local breeds and vegetal varieties, GMO-free planting, tradition, seasonality, and landscape preservation.

Along with better merchandise and relationships, Eco agriculture provides better governance of the food system, based on food sovereignty, fair prices, added value, which return to the farmer in the form of empowerment and higher self-esteem.

Economically, local trades help on developing the community, since the exchanges are within a smaller area/group of people, directly affected by them, and directly made by them. Also, the added value policy built by the dwellers increase the profit of the producer, not commonly rewarded in traditional agribusiness.

Briefly touching the concepts of Food Sovereignty, aligned with a sustainable agricultural model, which refers to the rights people have to decide what to cultivate, what and how to market their produce, and above all, food that is healthy and environmentally friendly to all people. All this chain is based on the consumption of local and seasonal produce, with minimum distance coverage. The farm to table concept is perfectly applicable, considering geographical distances and also the most direct form of contact between producer and consumer.

"Authenticity, local context, and local production are increasingly desirable attributes in the things we buy and the services we use. Local sells, and for that reason is a powerful antidote to mobility expansion. But design to enhance locality is easier said than done." (THACKARA, 2005, p.73). This scenario creates a solid ground for new ways of business and relationships. Social Innovation demands the design of strategies, concepts, and methodologies to fulfill the needs of modern society. The more conscious a society gets the more increases the demand for services and products matching its level of understanding and expectations. The agribusiness has become obsolete. There is an urgent need for a more sustainable, health/quality focused and fair trading model.

\section{Food made local}

The city of Rio de Janeiro, Brazil, has an initiative named Junta Local which is a successful example of SFSC. It was initially conceived by a college student as his graduation project, being from the beginning a bottom-up strategy. Junta Local is based on the fair trade of small agriculture, often organic, joined with artisan manufacturing of pastries and baked goods, cold cuts, beer, and ready to order food amongst others (there are even chemical-free cleaning products and pet food).

They define themselves as a "bunch" of people joined in a community who believe that "to eat well one must know the source of one's food and who produces it. (...) The platform values the human bond inside the food chain" (http://www.juntalocal.com/). At Junta Local, the conditions to broaden the access to good food are created by short- ending the food circuit and thinking on low- 
cost platforms, accessible to all.

The concept of fair trade is applied with the maker (producer/food handler) in the spotlight, making money circulate locally. The price is fair when there's profit for who produces/handles as much as for the environment and society. The gatherings are organized in two pre-set scheduled street markets per month, with the possibility of other venues on the remaining weekends, and weekly online purchase. The later was conceived first and aims at reaching out further than the areas covered by the street markets.

Currently, with the name "Sacola Virtual" ("Online Shopping bag") the online purchase is offered from Monday till Thursday, to be picked up at a preset location on Saturday. This process not only aids the customer to organize and plan his weekly purchase, but also helps the producers, who know, by Thursday, exactly what and how much needs to be produced, minimizing food waste (along with the investment, bearing in mind they are mostly small producers who can't afford risking their money on non-guaranteed sale).

According to their website," we're rethinking the food system bottom up so the producer receives more, you pay less and food waste is minimized". On the street markets, the interface between producer and consumer couldn't be better. There's a friendly atmosphere, where the community meets around food and bond is quickly formed when the clientele stops at the stall and chats with the producer. It is the perfect moment to connect the origin and end of the food chain and close the circle. From organic grown seasonal crops to artisan beer, it is all good, fair and local food. Junta Local has run a long way in presenting a new form of commerce.

Initially, the idea was shared with a handful of farmers and artisans. The first farmers market had about fifteen stalls, if so, but the principles have always been there, nice and clear. The worries about sustainability, fairness, and provenance of food sold were clearly stated. The reputation was built on this solid ground, and quickly, Junta Local had people lining up to be part of the bi-monthly market. The curatorship was carefully done, and along with their existence, a couple of producers have left the group, for they haven't responded to the ideals of the community.

As the market grew stronger and better known, the organization team fought for stability, legal documentation and support to the members. A set schedule was established with the municipality. Meetings started to be held periodically to organize and help the participants, and documents stating rules were produced, collectively. This almost horizontal organization is of paramount importance on the business model proposed by Junta Local.

Transparency on finances is another pillar. A new type of consumers started to flock, people who care about the origin and handling of their food, and did not mind paying a little extra for this added value. A trusting bond was rapidly intertwined between all the involved, from farmer to final consumer, who now knew the faces and hands of those manipulating their food. This relationship extends to the newly attracted and strengthens with the habitués each street fair. There is always a stall dedicated to the organization, interacting and giving support to both consumers and producers, showcasing initiatives such as waste reduction and management, selling reusable goblets, glass straws and the such

On street-fair days, this crew is also responsible for prompting new clients, informing them about the online purchase "Sacola Virtual", and reinforcing the links by advertising the next market venue, or a recently joined producer and so on. Their website incites the relationships amongst producers and between clients and sellers, displaying pictures and a short story of all members. With this rapport built with both ends of the cycle, the organization can constantly evaluate and respond to customers and providers' needs. 
The community and cultural links brought up by Junta Local involve, besides all the aspects mentioned above, the sense of ownership from those who participate, by occupying open urban areas: the streets, squares and surrounding areas of the market, thus connecting and bonding the society around the food chain matter.

\title{
4 Food and Design: tools for social innovation
}

\section{According to Ezio Manzini,}

\begin{abstract}
"Social innovation is a process of change emerging from the creative re-combination of existing assets (from social capital to historical heritage, from traditional craftsmanship to access advanced technology), the aim of which is to achieve socially recognized goals in a new way".
\end{abstract}

To which he adds that "it is a constellation of design initiatives geared toward making social innovation more probable, effective, long-lasting, and apt to spread."(MANZINI, 2014, p.32).

Considering what was priorly exposed, social innovation through design projects is the key to solving a range of urban-related issues, involving different sectors of the organized society, economic and environmental aspects. Because they are not directly from the above-mentioned areas, designers can shift from diverse knowledge camps, team up with different professionals and individuals, and perhaps see more clearly where the problem is heading, and the project alternatives for solving it. They can be both "triggers" or facilitators of initiatives.

Some concepts can be borrowed from the international Slow Food movement, founded in 1989 by Carlo Perini, in Italy. The first statement is: "We believe that everyone has a fundamental right to pleasure and consequently the responsibility to protect the heritage of food, tradition, and culture that makes this pleasure possible". (Petrini, Carlo Slow Food Nation: Why Our Food Should Be Good, Clean and Fair. Milano: Rizzoli, 2007). And he goes on, stating the importance of educating consumers as co-producers, who become engaged actors on the production process as they build awareness on the entire food chain.

The Junta Local project can also be put under an interesting action plan document compiled by the French Ministry of Food, Agriculture and Fishing: food of guaranteed quality, diversity and durability, by recreating a trust bond between producers and consumers. The four axis for the development of the SFSC are:

- make the short chains widely known, and diffuse them

- adapt the techniques and bring information to the farmers to meet the needs of the short chains

- favor the placement of family-scale planters in short chains

- foment and organize the short chains

After deeper analysis, using the SWOT chart (Strengths, Weaknesses, Opportunities, and Threats) and the above-described outlines put Junta Local in a favorable position as an active character in the short food supply chains. The group has acted as an incubator for all these small businesses, with some potential to grow even further, as graphically shown: 


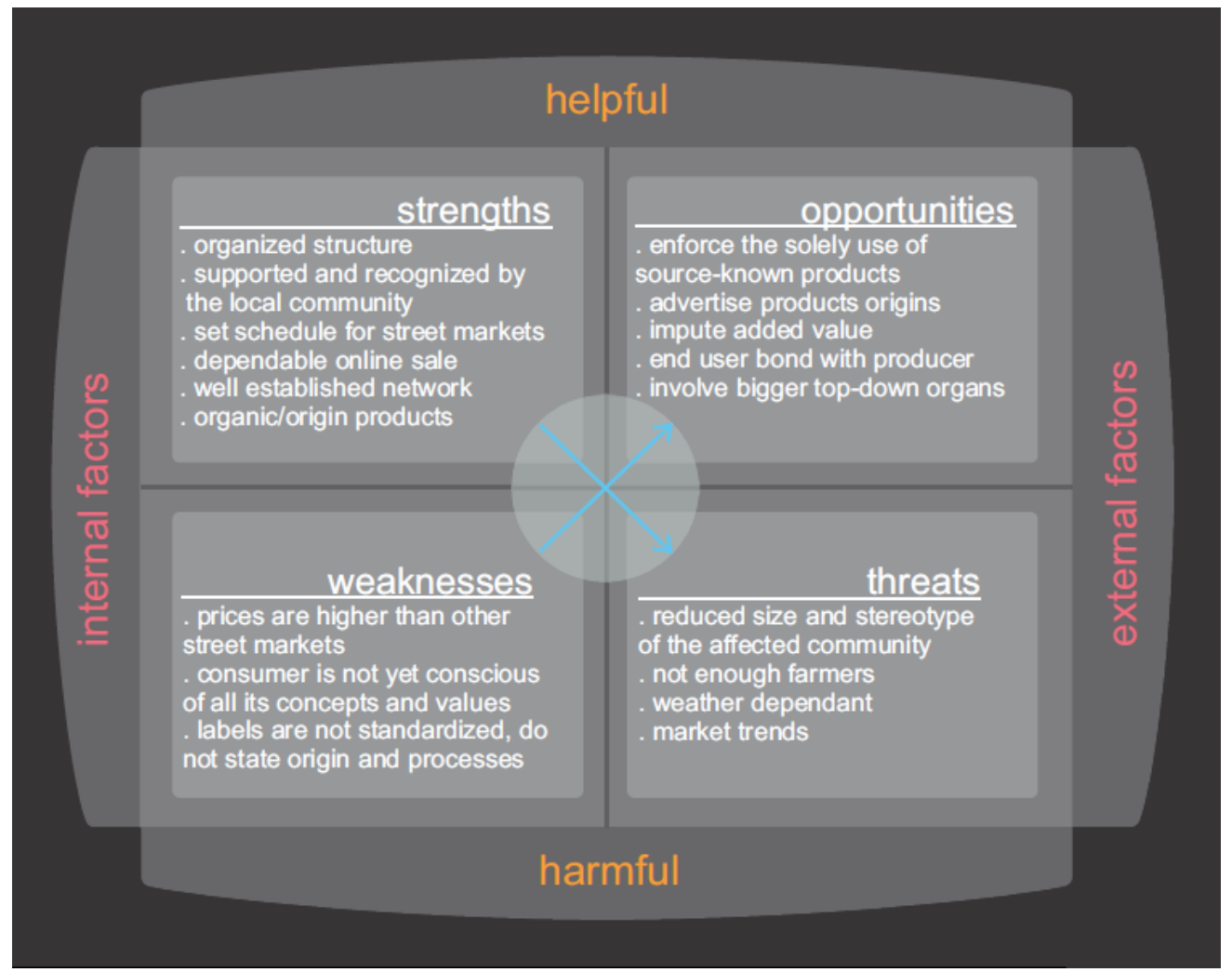

\section{Food from farm to table}

To conclude this brief study, it must be noted that agribusiness can no longer be seen as the only feasible way to feed the population. Sustainable planning has been gaining strength, and sure needs incentives. Small and preferably organic cultures are slowly taking place, and reaching more people, especially in urban centers.

Education to food quality is paramount, and that involves bigger actors, such as the municipality and public policies. While there's so much worry about eating better, to some people the issue is still as basic as eating on a daily basis. The challenge is to make this way of living more tangible, accessible and understood to as many as possible, in an economically competitive manner. Feeding a family with less poison and more nutrients shouldn't be more expensive. One must go back in the time when the crops were well known, seasons were waited for and their timing respected, and people were more connected to the land.

The patrons must be sure they are paying more for products that are, from origin to end, of higher quality than their regular supermarket equivalents. The challenge rests in building an evergrowing network of more conscious and active customers, who not only can afford the better merchandise, but also understand the value of what they are ingesting, and the importance of knowing their food. That touches the overall price of what's sold, and the feeling people have of that. Access to better food should not be restrained to upper-class groups, and the impression that being concerned about the provenance of the food is only attainable by a few privileged people has to be fought. 


\section{References}

ARRUDA, A (org). Ensaios sobre Design, Cultura e Tecnologia Design e Inovação Social, Editora Edgard Blücher Ltda; 2017.

DESMOND, N., SIEBERT, J. Toward Better Defining the Field of Agribusiness Management. International Food and Agribusiness Management, Review, 2009.

DEVERRE, C.; LAMINE, C. Les systémes agroalimentaires alternatifs. Une revue de travaux anglophones en sciences sociales. Econ. Rural. 2010, 317, 5773.

GOODMAN, D. The quality turn' and alternative food practices: Reflections and agenda. J. Rural Stud. 2003, 19, 17.

IBERY, B.; MAYE, D. Alternative(shorter) food supply chains and specialist livestock products in the Scottish- English borders. Environment and Planning A 37 (5): 823844.2005

MANZINI, E., STASZWOSKI E. (editors). Public and Collaborative: Exploring the Intersection of Design, Social Innovation and Public Policy, DESIS Network, 2013.

MANZINI, E. Making Things Happen: Social Innovation and Design. Design Issues: Volume 30, Number 1 Winter 2014.

OLIVEIRA, A. J., FRANZATO, C., DEL GAUDIO, C (org). Ecovisões projetuais: pesquisas em design e sustentabilidade no Brasil. Rio de Janeiro: Editora Edgar Blücher, 2017.

PETRINI, C., Slow Food Nation: Why Our Food Should Be Good, Clean and Fair. Milano. Rizzoli; 2007.

DE SCHUTTER, O.; VANLOQUEREN, G. The New Green Revolution: How Twenty-First-Century Science Can Feed the World. Solutions Journal. Volume 2, Issue 4; Aug 2011.

SONKA, S.; LINS, A. Production agriculture as a knowledge creating system. International Food and Agribusiness Management Review. 02. 1999.

THACKARA, J. How to thrive in the next economy. Thames and Hudson Publication; 2015.

THACKARA, J. In the bubble: designing in a complex world, MIT Press; 2015.

WISKERKE, J.S.C. On places lost and places regained: Reflections on the alternative food geography and sustainable regional development, International Planning Studies, 14 (4): 369387. 2009

http://www.urbagri.org/site/medias/PlanActionsRenforcerCircuitsCourts.pdf Ministérie de L'Alimentation, de L'Agriculture et de la Pêche. Renforcer le lien entre agriculteurs et consommateurs, access in June 2018.

https://www.helsinki.fi/en/news/society-economy/traceability-of-fresh-vegetables-from-farm-totable, access in May 2018

http://www.juntalocal.com, access in May 2018. 